\title{
Motivations for using social media: comparative study based on cultural differences between American and Jordanian students
}

\author{
Heba AL-Quraan* \\ Department of Management Information Systems, \\ College of Information Technology and Computer Science, \\ Yarmouk University, \\ 21163, Irbid, Jordan \\ Email: heba.quraan@yahoo.com \\ *Corresponding author
}

\section{Emad Abu-Shanab}

Department of Accounting and Information Systems,

College of Business and Economics,

Qatar University,

P.O. Box. 2713, Doha, Qatar

Email: eabushanab@qu.edu.qa

\section{Shadi Banitaan}

Department of Mathematics,

Computer Science and Software Engineering,

College of Engineering and Science,

University of Detroit Mercy,

48221, Detroit, MI, USA

Email: banitash@udmercy.edu

\section{Heyam Al-Tarawneh}

Counseling Department, Hayat Universal School, P.O. Box. 6124, Doha, Qatar

Email: heyam.altarawneh@hayatschool.com

\begin{abstract}
Social network sites (SNSs) have gained popularity over the last decade. Students use SNSs according to their personal differences, which are influenced by cultural and demographic factors. This paper proposed a model that included four basic factors that act as predictors of continuous use of SNSs. The factors are personal, social, educational and entertainment. The first objective of this study is to investigate the influence of the predictors on the dependent variable. Results indicated a full support of our proposed model, with an $R^{2}=0.296$. The second objective is to explore the differences between US and Jordanian students. An Analysis of variance (ANOVA) test was conducted and results yielded significant cultural differences and stronger than gender
\end{abstract}


differences. The test yielded 17 significant differences compared to 10 based on gender. This research calls for more research that tries to explore what cultural factors cause such differences.

Keywords: comparative study; continuous use of SNs; cultural differences; Jordan; social networks; USA.

Reference to this paper should be made as follows: AL-Quraan, H., Abu-Shanab, E., Banitaan, S. and Al-Tarawneh, H. (2017) 'Motivations for using social media: comparative study based on cultural differences between American and Jordanian students', Int. J. Social Media and Interactive Learning Environments, Vol. 5, No. 1, pp.48-61.

Biographical notes: Mrs Heba Al-Quraan earned her both Bachelor and Master degrees in Management Information Systems from Yarmouk University in Jordan. Her research interests include E-government, technology acceptance, E-learning and medical informatics. Al-Quraan worked as a part-time lecturer in the College of Information Technology and Computer Science at Yarmouk University from 2014 to 2015 .

Prof Emad Abu-Shanab earned his $\mathrm{PhD}$ in business administration, in the MIS area from Southern Illinois University - Carbondale, USA, his MBA from Wilfrid Laurier University in Canada, and his Bachelor in civil engineering from Yarmouk University (YU) in Jordan. He is a Full Professor of e-government in YU, and an Associate Professor in MIS in Qatar University. His research interests include E-government, technology acceptance, E-marketing, E-CRM, Digital divide, IT project management and E-learning. Published many articles in journals and conferences, and authored three books in e-government. Prof. Abu-Shanab worked as an Assistant Dean for students' affairs, quality assurance officer in Oman and the director of Faculty Development Center at YU. He was the MIS Department Chair for the year 2015-2016, and now he is an Associate Professor in the Accounting and Information Systems Department, College of Business and Economics, at Qatar University.

Dr Shadi Banitaan is currently an Assistant Professor at the Mathematics, Computer Science and Software Engineering Department at the University of Detroit Mercy. His research interests include software engineering and data mining. He is a member of the Association for Computing Machinery (ACM), a member of the Institute of Electrical and Electronic Engineers (IEEE) and a member of the IEEE Computer Society. He received B.S. in Computer Science from Yarmouk University, an M.S. in Computer and Information Sciences from Yarmouk University, and a $\mathrm{PhD}$ in Computer Science from North Dakota State University. He taught for 5 years at the University of Nizwa, Oman. He joined the University of Detroit Mercy in 2013.

Mrs Heyam Al-Tarawneh graduated from University of Jordan with a Bachelor in education psychology (1987), and a higher diploma in special education (1994). She earned her master degree from Yarmouk University in education psychology in 2010 while working in the ministry of education as a students' counsellor. Her extensive experience in education and work with students enabled her to publish few articles in social networks and the relation with students' performance and other topics related to technology adoption. She is working now in a private school in Qatar. 


\section{Introduction}

Social media is defined as a set of web-based services that are used by a number of persons who have the similar interests, preferences or professions, via the internet (Wu et al., 2014). The objective of social media is to provide a useful platform that enables individuals to share their knowledge, content and experiences.

Different types of social media are considered as tools or channels that facilitate the communication, collaboration and cooperation among people. Users can contact others individually or within groups utilising such networks. Some researchers consider social networks (SNs) as an open domain or anti-corruption tool that participates in building a culture of transparency (Bertot et al., 2010). Persons whether they are students, workers or instructors can obtain information or gain knowledge from different sources once they needed, and in a convenient fashion. SNs offer many types of data in several forms such as text, audio, video, photos and so on. People (regardless of their experience level in SN applications) can share their ideas, knowledge, experience and expertise with others.

Social media channels have developed rapidly and witnessed a huge demand for new applications in order to keep up with individuals' needs, desires and expectations. Also, it served the purpose of facilitating organisational knowledge sharing process (Chow and Chan, 2008). Users can conduct meetings from anywhere and anytime by utilising the applications offered by SNs such as Facebook, Viber, Skype and others.

With the fast developments of SN sites (SNSs), users became more experienced in their decision-making process, especially after the revolution of mobile devices. Users can browse the internet anywhere and anytime with the support of these portable/functional devices. It is difficult to determine users' motivations or interests during a specific point in time as they can easily switch between applications because of the large available alternatives in front of them (Wu et al., 2014).

Nowadays, social media has changed our lifestyle; it became an essential part of our daily activities and a major motive for internet use. A study utilising a qualitative survey distributed on Estonian population has clarified two basic factors that are acting as major motives for using the internet, they are: social media and entertainment (SME), and work and information (WI). WI was positively associated with high educational level, ethnic majority status and the frequency of using SNSs at work or at school (Realo et al., 2011).

Quan-Haase and Young (2010) have compared two types of social media networks, Facebook and Instant messaging in order to determine the major use for each one. They concluded that the common use of Facebook is to have fun and to know about the social activities. Whereas people use the Instant messaging in order to maintain and develop the relationships between persons.

In all, 10 gratifications were the answer for a study titled as "Why people use social media: a uses and gratifications approach" which aimed to discover the major purposes for using the social media. The 10 gratifications are social interaction, information seeking, pass time, entertainment, relaxation, communicatory utility, convenience utility, expression of opinion, information sharing and surveillance/knowledge about others (Whiting and Williams, 2013).

The paper consists of four sections: the first one is the literature review which explains number of proposed factors representing the potential reasons for using the social media sites or networks. The next section is about the methodology which is 
adopted in the study to serve its purpose and objective(s). The third one is to discuss the data analysis results. Finally, the conclusion and future work are described in detail.

\section{Literature review}

This section contains a set of studies that were performed in the same domain of this work. Three sub-sections represent the suggested predictors for our proposed model for this study, and the predictors show the reasons or purposes behind using the social media sites.

\subsection{Personal purposes and entertainment purposes}

Many persons suffer from different psychological problems such as feeling alone, selfinferiority, lack of confidence, depression and other problems. Such individuals tend to create their own virtual world which satisfies their interests, needs and demands. Such virtual world is depicted through their use of social media, where they may find solutions for the problems they face. A previous work studied the effect of using SNSs on satisfying the self-esteem based on four major scales as follows: Rosenberg's self-esteem scale, Lai's personality test, a Facebook usage scale and a Facebook addiction scale (FAS) (Hong et al., 2014). They can express their feelings to others with similar interests or at least those who could face similar situations. Hong et al. (2014) attempted in their study to explain the relationship between Facebook use and Facebook addiction. Finally, they have concluded that people with self-inferiority tend to use Facebook, while people who suffer from depression will have Facebook addiction (Chen and Kim, 2013). Based on that, social media may provide competing platforms to enable individuals to develop their ideas and become more creative and innovative (Van Dijck, 2013).

Two major perspectives are reported in the literature, which present the motives and reasons for using social media networks. The first one tends to depend on the rational and goal-oriented use of SNSs, such view is called the utilitarian motives. Another perspective is pleasure oriented and is called hedonic motives. The study depended on such classification concluded that social media sites play a significant role in supporting both types of motives. Users may have an influence on their friends and encourage them to join such applications. Basically, four gratifications were observed namely affection, leisure, immediate access and coordination purposes ( $\mathrm{Xu}$ et al., 2012). Organising vacation trips is another intention for using SNSs, where the role of social media sites helps tourists to determine what to use and diverse trip elements which has a positive impact on market trends (Parra-López et al., 2011).On the other side, the increasing growth of such sites makes it so important for parents to be more responsible towards their children when using them. Most of the teens spend most of their time playing on the gaming sites, and other social media sites which can be considered unhealthy environment for children and adolescent (Fernández, 2011). So, using social media might result in different results where some would face negative consequences (Frehat and Abu-Shanab, 2014) and others might see huge benefits from such experience. Different applications will result in different results and different purposes by users will yield different results also. For example, a study conducted on university students in USA and Europe and concluded that there is a negative relationship between using SNs 
and students' Grade Point Average. The authors assured that the way of using such sites were disrupted (Karpinski et al., 2013).

\subsection{Social purposes}

Isolation is a prominent factor that is related to SNSs use (Abu-Shanab and Frehat, $2015 b$ ). The authors reached such conclusion based on data analysis of 302 responses on a survey that measured the influence of trust, intensity of use, satisfaction, isolation and social participation on behavioural intentions. Results supported only isolation and intensity of use, and failed to support the other three factors. Brandtzæg and Heim (2009) have investigated the percentage of people using SNSs and their own motives to use such applications by utilising a quantitative and qualitative research design. They concluded that most people sampled are using social media in order to contact others, find new friendships and just to socialise. Another research explored the impact of public relations related to activities conducted using social media, in which the value of social media has been determined as a public relations tactic. The findings supported the notion that social media power is an evidence of its effectiveness as a communication tool (Taylor and Kent, 2010). The use and gratifications (U and G) of online SNs in terms of creating an identity in a social form are the main results which have been discovered after a study conducted among a set of 12- to 14-year-old girls from Ireland (Dunne et al., 2010). Another study explored the bad and good influences of Facebook and concluded that the highest perceived benefit of SNSs is finding old and new friends, while the highest perceived downside of SNSs is its influence on addiction on such applications and isolation from face-to-face environment (Abu-Shanab and Al-Tarawneh, 2013). The study utilised 206 responses on a survey distributed on university students in Jordan.

\subsection{Educational purposes}

Social media plays a significant role in the educational sector. Many schools, universities and teachers are using social media as a tool for education. In the medical sector, an experiment was done at Penn State College of Medicine. The experiment utilised many social media tools to be used by 4 th year university student in their elective courses. Students were supposed to provide a qualitative as well as quantitative evaluation about the courses at the end of semester to understand their performance. The research result was that integrating the tools of social media into medical programs offers many benefits over the conventional ways in education, and was considered a significant step to prepare a well-equipped and educated staff for future who would adopt any new technology conveniently (George and Dellasega, 2011).

Moran et al. (2011) have claimed that the online videos, podcasts and wikis are reported as the most valuable social media tools in the learning process, through which students can get their extra assignments, comments on posts about particular problem in the course and they can obtain more information and examples for better understanding. SNSs are seen as a useful tool that successfully facilitates a collaborative learning process (Moran et al., 2011). Another study distributed an online survey on first year students at a British university, which investigated Facebook as a tool that can be used to achieve educational purposes in a social context. The study concluded that Facebook helps students to find new friends who can assist them in their learning process as well as keep 
in touch with their friends and families (Madge et al., 2009). In addition, when trying to observe the role of adopting mobile computing devices (smartphones) and social media networks capabilities in higher education, a study concluded that integrating SMNs and mobile technology will lead to more students' engagement in content creation process (Gikas and Grant, 2013).

The relationship between personal learning environment (PLE), social media and selfregulated learning was the aim of a study conducted by Dabbagh and Kitsantas (2012). The authors had concluded that not all of students have enough knowledge management skills to build a PLE which meets their learning process needs, but they act as a selfregulated learner in order to acquire, manage and develop PLE via adopting social media tools.

The term of massive open online courses (MOOCs) has been developed to be used as a new technique or strategy for learning and teaching aims to create and improve the learning process inputs and output as well (Guàrdia et al., 2013). The idea was derived basing on the learners perspectives in order to empower them to encourage critical thinking and collaboration, enhance competence-based deliverables and facilitate assistance using information and communication technology (ICT) tools and media. Students who are using MOOCs can react to the comments, chat easily by optimising social media and other ICT tools (Pelet et al., 2015).

In the Jordanian context, a study that utilised responses from 113 students on issues related to the influence of SNs on high school students' performance and its relationship to performance (Abu-Shanab and Al-Tarawneh, 2015a). The authors used students GPA as a surrogate for academic performance and concluded that the longer the time spent on Facebook, the worse students' performance would be (neglecting their duties and assignments).

The findings of a comparative study between Americans and Koreans were related to the cultural differences in the motivations of using SNSs (Kim et al., 2011). The researchers proposed five basic factors as the determining motives for using SNSs by American and Korean students and they are seeking friends, seeking social support, seeking entertainment, seeking information and seeking convenience. Another study has adopted similar factors to study the motivations and reasons behind using SNSs as follows: socialising, entertainment, information and seeking self-status by distributing 1715 surveys to college students basing on their hometown, demographics such as the gender, and their year in school (Park et al., 2009). Previous studies mentioned above have guided our review of the literature and structured our proposition under four major sections: personal purposes, social purposes, educational and entertainment purposes.

\section{Methodology}

Social media is overwhelming our lives and became an important part of our daily activities. This study explored the literature and concluded four major factors that would have a significant influence on the intention to continue using the social media. The aim of study is twofold: the first is to examine the factors influencing the intention to continue using the social media. The four factors expected to influence the use of social media are the following and as shown in Figure 1: personal, social, educational and entertainment. The second objective is to explore the differences between American and 
Jordanian students in relations to all the factors (and their sub-concepts) used in the study. Table 1 summarises the meaning of each proposed purpose of use.

Figure 1 The regression model

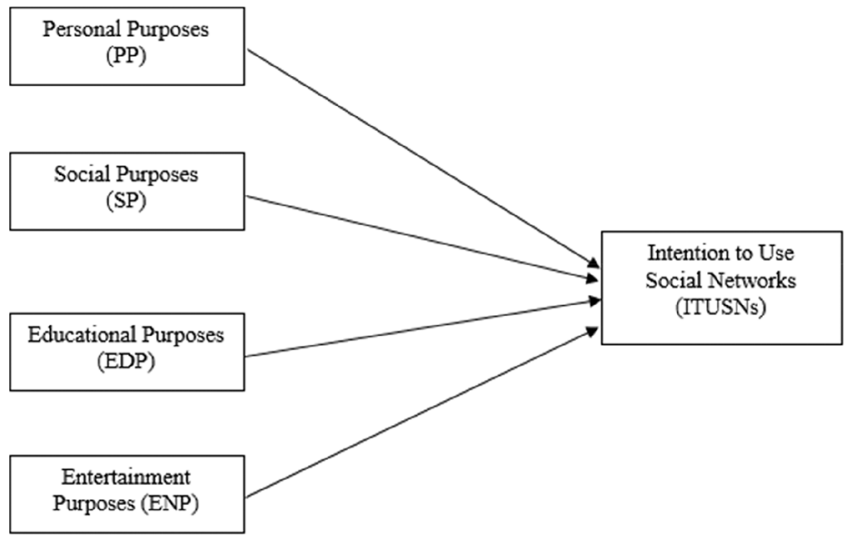

Table 1 Factors of using SNSs and it explains the meanings of each purpose

\begin{tabular}{|c|c|c|}
\hline Purposes/motives & Definition & References \\
\hline Personal & $\begin{array}{l}\text { To get respect, self-esteem, } \\
\text { confidence, creativity and being able } \\
\text { to compete }\end{array}$ & $\begin{array}{l}\text { Bolton et al. (2013) and } \\
\text { Valenzuela et al. (2009) }\end{array}$ \\
\hline Social & $\begin{array}{l}\text { To socialise with others, find new } \\
\text { friends, contact with others with } \\
\text { similar interests }\end{array}$ & $\begin{array}{l}\text { Bolton et al. (2013), Valenzuela } \\
\text { et al. (2009), and Lovejoy and } \\
\text { Saxton (2012) }\end{array}$ \\
\hline Educational & $\begin{array}{l}\text { To find information, news, conduct } \\
\text { research, share knowledge and } \\
\text { experience, and personalise the } \\
\text { learning process }\end{array}$ & $\begin{array}{l}\text { Bolton et al. (2013) Valenzuela } \\
\text { et al. (2009), and Lovejoy and } \\
\text { Saxton (2012) }\end{array}$ \\
\hline Entertainment & $\begin{array}{l}\text { To have fun, enjoy time or just spend } \\
\text { time }\end{array}$ & Bolton et al. (2013) \\
\hline
\end{tabular}

\subsection{Instrument used}

The paper used previous research to build an instrument that would be used in this study. A questionnaire is a good instrument to measure responses from a large sample of respondents. Also, a structured survey would be easier to compare how different samples can differ or be similar with respect to their perceptions towards certain concepts. The instrument used in this study included three sections; the first section illustrated the objectives of research. The second section included simple demographic data such as gender and age. The instrument included no identification questions exposing respondents' identity to probe more accurate responses as respondents feel free when filling the survey. The final section included 17 items measuring the four constructs shown in the research model, and the dependent variable. The four constructs used in this study were measured using five items for each. 
The instrument utilised a 5-point Likert scale with 1 representing total disagreement, and 5 representing a total agreement. With such type of scale, it is common in social sciences to allocate the ranges of responses when calculating the mean into the following categories: $1-2.33$ is considered a low mean; $2.34-3.66$, a moderate mean; and $3.67-5$, a high mean. Such categorisation is based on dividing the total interval by three (categories), which yields the following: $(5-1) / 4=1.33$ for each interval. Once the instrument was ready, content analysis was conducted using five master students who participated in translating the instrument from Arabic to English and vice versa [utilising the backward translation method proposed by Brislin (1976)]. The description of items of the instrument is shown in Table 2 with the estimated means and standard deviations.

Table 2 Item descriptions, means and standard deviations

\begin{tabular}{lcc}
\hline Item description & Mean & Std. dev. \\
\hline P1: .. to get respect and appreciation from others & 2.65 & 1.239 \\
P2: .. to feel confident and achieve self-esteem & 2.72 & 1.199 \\
P3: ... to develop ideas for my life & 3.67 & 1.223 \\
P4: ... to better compete with others & 2.77 & 1.290 \\
P5: ... to get help and support from others & 3.49 & 1.161 \\
\hline Total construct means and standard deviation (personal purposes) & 3.063 & 0.935 \\
\hline S1: ... to communicate with people who I do not know & 3.22 & 1.323 \\
S2: ... to communicate with people with similar interests & 3.55 & 1.097 \\
S3: ... to find new friends I never met & 2.84 & 1.301 \\
S4: ... to sustain my existing relationships & 3.74 & 1.102 \\
S5: ... to revive my old abandoned relationships & 3.41 & 1.213 \\
Total construct means and standard deviation (social purposes) & 3.353 & 0.823 \\
ED1: ... to find new and useful information I need & 4.11 & 0.978 \\
ED2: ... to get help in completing and doing assignments & 3.59 & 1.202 \\
ED3: ... to conduct research about specific problem & 3.47 & 1.196 \\
ED4: ... to share with others my knowledge and expertise & 3.54 & 1.088 \\
ED5: ... to know about assignments deadlines and requirements & 3.71 & 1.187 \\
Total construct means and standard deviation (educational purposes) & 3.684 & 0.872 \\
\hline EN1: ... to have fun, and enjoy my time when alone & 4.06 & 0.992 \\
EN2: ... just to pass time & 3.97 & 1.047 \\
EN3: ... to enjoy my time within groups & 3.16 & 1.227 \\
EN4: ... to explore my sense of humor with others & 3.59 & 1.091 \\
EN5: ... to listen to music, and see videos posted by others. & 3.88 & 1.152 \\
\hline Total construct means and standard deviation (entertainment purposes) & 3.729 & 0.779 \\
\hline CITU1: I will continue using social media (SNSs) in the future & 4.28 & 0.878 \\
CITU2: I will use more social media types & 3.64 & 1.098 \\
CITU3: I expect that I will continue using social media (SNSs) & 4.22 & 0.873 \\
Total construct means and standard deviation (continuous use of SN) & 4.045 & 0.782 \\
\hline
\end{tabular}

... I use social networks ... 


\subsection{The sample and sampling process}

The authors distributed the surveys and collected data from university students in two countries at the same time. The sampling process in both countries was based on voluntary bases. Faculty members were asked whether they would allow the researchers to distribute the survey on students and supervise the process of collecting data. In class setup, students were asked whether they volunteer for such task and were not forced to do that. Finally, not extra credit or incentive was given to students in for filling the survey. Research concluded that context, sample and topic were significant factors influencing research results more than being student or not (Peterson and Merunka, 2014).

The first sample included 118 usable surveys collected from students in the University of Detroit Mercy in the USA. The second sample included 111 usable surveys collected from students in Yarmouk University in Jordan. The sample included 113 males (49.3\%) and 116 females $(50.7 \%)$. As for age, the sample included 75 students with age less than 20 years (32.8), 152 students with age from 20 to 30 years $(66.4 \%)$ and 2 students with age more than 30 years $(0.9 \%)$.

For such Likert scale, a value between 1 and 2.33 indicates a low perception, a value between 2.33 and 3.67 would indicates a medium perception, and finally a value between 3.67 and 5 would indicate a high perception.

\section{Data analysis and discussion}

The first step is to explore the overall item means and standard deviations. Table 2 includes an estimate individual items and the overall variable. Results shown in Table 2 indicate a majority of medium perceptions regarding the factors related to the personal and social factors. On the other hand, higher perceptions are witnessed for entertainment and educational factors. Overall, personal factor yielded medium perception $($ mean $=3.063)$, social factor yielded medium perception $($ mean $=3.353)$, educational factor yielded high perception $($ mean $=3.684)$ and finally, entertainment factor yielded high perception $($ mean $=3.729)$. The overall perception regarding the intention to continue using SNs yielded high value (mean $=4.045$ ).

The second step in analysis is to estimate the overall construct value for all five constructs and use such value in multiple regression to estimate the influence of such four factors on the continuous intention to use. To estimate regression, the first step was to see whether some outlier values (responses) are distorting our analysis. The initial estimate of regression called for one instance only and thus was removed from the further analysis. The total sample size used for regression totalled 228 surveys.

Multiple regression results are shown in Table 3, where the result of regression indicated a significant model that predicts the continuous intention to use SNs (CITU). The coefficient of determination $R^{2}=0.296\left(\mathrm{~F}_{4,223}=23.435, p<0.001\right)$, which means that the variability of CITU can be explained by $29.6 \%$. The coefficient table (Table 3 ) indicates also a support for all factors in predicting the CITU with differential significance level. 
Table 3 The regression coefficient table

\begin{tabular}{lccccc}
\hline & \multicolumn{5}{c}{$\begin{array}{c}\text { Stand. } \\
\text { Coeff }\end{array}$} \\
\cline { 2 - 6 } Constructs & $B$ & Std. error & Beta & $t$ & Sig. \\
\hline Constant) & 1.566 & 0.266 & & 5.890 & 0.000 \\
Personal purposes (PP) & 0.116 & 0.058 & 0.140 & 2.001 & 0.047 \\
Social purposes (SP) & 0.157 & 0.063 & 0.167 & 2.488 & 0.014 \\
Educational purposes (EDP) & 0.176 & 0.058 & 0.199 & 3.032 & 0.003 \\
Entertainment purposes (ENP) & 0.257 & 0.059 & 0.260 & 4.339 & 0.000 \\
\hline
\end{tabular}

Dependent variable: Continuous intention to use SNs (CITU).

The values of standardised betas in the coefficient table indicate that entertainment purposes are the most influential factor on CITU (beta $=0.260$ ), followed by educational purposes (beta $=0.199$ ). The other two factors were also significant in predicting CITU SNs, with beta values lower than the previously mentioned two (social purposes beta $=0.176$ and personal purposes beta $=0.140$ ). Figure 2 shows the resulting research model.

Figure 2 Resulting research model with beta values

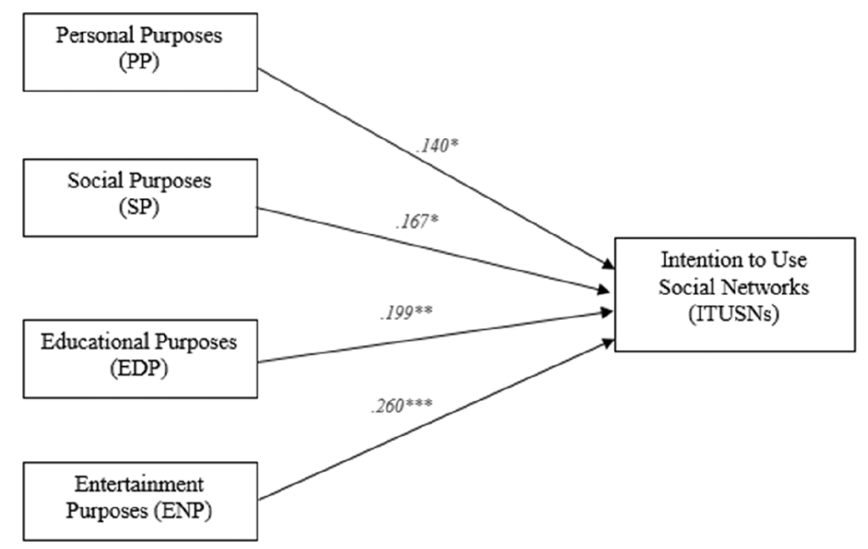

The second research objective is related to the focus of this research, where we aim at contrasting the results of this study between the two cultures. We assume that the cultures of the two countries will impose differences in behaving on SNs. The culture factor will be treated as a black box, where we are not interested in exploring the reasons behind such differences. Still, this exploratory study will try to see whether differences exist between the two groups of students.

To test for differences between the two groups, a one-way ANOVA was conducted using student country as a differentiating factor. To see whether the differences are substantial or not, the same test was done on gender. Gender is a significant determinant in research (AbuShanab et al., 2010; Abu-Shanab and Al-Jamal, 2015a) and if culture (country) incurs a difference more than gender, we rest our argument. The test utilised an ANOVA test using an alpha value $=0.05$. All values of $p<0.05$ would mean that the difference is significant based on country or based on gender. The first test compared all 
items of the survey (results are shown in Table 4). The second test compared the overall constructs based also on gender and country (results are shown in Table 5). We also estimated the means and standard deviations for the two categories of country (i.e. the mean of US students' responses vs. the means for Jordanian students' responses).

Table 4 ANOVA test for individual items based on country and gender

\begin{tabular}{|c|c|c|c|c|c|c|c|}
\hline Item & Country & Mean & Std.Dev. & $F$ & Sig. & $F$ & Sig. \\
\hline & USA & 2.42 & 1.219 & & & & \\
\hline \multirow[t]{2}{*}{ PP1 } & Jordan & 2.87 & 1.207 & 8.013 & 0.005 & 0.159 & 0.690 \\
\hline & USA & 2.47 & 1.257 & & & & \\
\hline \multirow[t]{2}{*}{ PP2 } & Jordan & 2.97 & 1.066 & 10.568 & 0.001 & 3.222 & 0.074 \\
\hline & USA & 3.02 & 1.293 & & & & \\
\hline \multirow[t]{2}{*}{ PP3 } & Jordan & 4.34 & 0.640 & 94.614 & 0.000 & 11.180 & 0.001 \\
\hline & USA & 2.54 & 1.323 & & & & \\
\hline \multirow[t]{2}{*}{ PP4 } & Jordan & 3.00 & 1.202 & 7.499 & 0.007 & 0.023 & 0.879 \\
\hline & USA & 3.09 & 1.237 & & & & \\
\hline \multirow[t]{2}{*}{ PP5 } & Jordan & 3.90 & 0.908 & 30.840 & 0.000 & 2.796 & 0.096 \\
\hline & USA & 2.70 & 1.341 & & & & \\
\hline \multirow[t]{2}{*}{ SP1 } & Jordan & 3.76 & 1.072 & 42.848 & 0.000 & 2.600 & 0.108 \\
\hline & USA & 3.35 & 1.162 & & & & \\
\hline \multirow[t]{2}{*}{ SP2 } & Jordan & 3.76 & 0.984 & 8.079 & 0.005 & 4.497 & 0.035 \\
\hline & USA & 2.50 & 1.380 & & & & \\
\hline \multirow[t]{2}{*}{ SP3 } & Jordan & 3.19 & 1.116 & 17.027 & 0.000 & 0.795 & 0.374 \\
\hline & USA & 3.75 & 1.136 & & & & \\
\hline \multirow[t]{2}{*}{ SP4 } & Jordan & 3.72 & 1.068 & 0.054 & 0.817 & 1.638 & 0.202 \\
\hline & USA & 3.25 & 1.174 & & & & \\
\hline \multirow[t]{2}{*}{ SP5 } & Jordan & 3.58 & 1.240 & 4.229 & 0.041 & 0.001 & 0.973 \\
\hline & USA & 3.80 & 1.116 & & & & \\
\hline \multirow[t]{2}{*}{ EDP1 } & Jordan & 4.44 & 0.670 & 27.033 & 0.000 & 9.891 & 0.002 \\
\hline & USA & 3.12 & 1.301 & & & & \\
\hline \multirow[t]{2}{*}{ EDP2 } & Jordan & 4.07 & 0.860 & 42.042 & 0.000 & 8.669 & 0.004 \\
\hline & USA & 3.04 & 1.302 & & & & \\
\hline EDP3 & Jordan & 3.91 & 0.873 & 34.211 & 0.000 & 9.929 & 0.002 \\
\hline
\end{tabular}

Results in Table 4 indicated that 17 out of 23 items were significantly different when compared based on country, but only 9 out of 23 were significantly different when compared based on gender. Such result supports our notion of the importance of culture influence. The differences were mostly focused on personal and social purposes of using SNs. In the same table, we can see also that the Jordanian means were higher than US means, for almost all items (significant items). It is important to mention that only significant results need to be taken into consideration. The second test shown in Table 5 indicated also a more prevalence of differences between the two cultures for the overall 
construct values. Such result supports also our remise in this research. Similarly, the means of Jordanian students were higher than US students.

Table 5 ANOVA test for overall constructs based on country and gender

\begin{tabular}{|c|c|c|c|c|c|c|c|}
\hline \multirow[b]{2}{*}{ Construct } & \multirow[b]{2}{*}{ Country } & \multirow[b]{2}{*}{ Mean } & \multirow{2}{*}{$\begin{array}{c}\text { Std. } \\
\text { deviation }\end{array}$} & \multicolumn{2}{|c|}{ Country based } & \multicolumn{2}{|c|}{ Gender based } \\
\hline & & & & $F$ & Sig. & $F$ & Sig. \\
\hline \multirow[t]{3}{*}{ Personal } & USA & 2.707 & 1.016 & 39.378 & 0.000 & 3.501 & 0.063 \\
\hline & Jordan & 3.421 & 0.653 & & & & \\
\hline & Total & 3.054 & 0.928 & & & & \\
\hline \multirow{3}{*}{$\begin{array}{l}\text { Social } \\
\text { purposes }\end{array}$} & USA & 3.111 & 0.868 & 21.854 & 0.000 & 1.000 & 0.318 \\
\hline & Jordan & 3.598 & 0.690 & & & & \\
\hline & Total & 3.348 & 0.822 & & & & \\
\hline \multirow{3}{*}{$\begin{array}{l}\text { Educational } \\
\text { purposes }\end{array}$} & USA & 3.304 & 0.985 & 56.237 & 0.000 & 14.925 & 0.000 \\
\hline & Jordan & 4.083 & 0.489 & & & & \\
\hline & Total & 3.683 & 0.874 & & & & \\
\hline \multirow{3}{*}{$\begin{array}{l}\text { Entertainment } \\
\text { purposes }\end{array}$} & USA & 3.874 & 0.806 & 8.113 & 0.005 & 0.917 & 0.339 \\
\hline & Jordan & 3.584 & 0.725 & & & & \\
\hline & Total & 3.732 & 0.780 & & & & \\
\hline \multirow{3}{*}{$\begin{array}{l}\text { Continuous use } \\
\text { purposes }\end{array}$} & USA & 3.932 & 0.832 & 6.189 & 0.014 & 5.386 & 0.021 \\
\hline & Jordan & 4.183 & 0.683 & & & & \\
\hline & Total & 4.054 & 0.772 & & & & \\
\hline
\end{tabular}

\section{Conclusion and future work}

This research tried to explore how students perceive the purposes of using SNs. The objectives of research were attained using a survey designed to probe student's perception regarding four major dimensions (types of purposes): personal, social, educational and entertainment. The first objective was to see whether the four purposes will significantly influence the continuous intention to use SNs. Results indicated a full support of our proposed research model with a coefficient of determination equal to 0.296 .

The second objective was to explore whether differences exist between the perceptions of US students and Jordanian students. An ANOVA test was conducted on the same data utilising the differences based on gender and country. Results indicated a stronger influence of culture (country) than gender influence. Such results support our assumptions. Also, our results indicated that means of responses for Jordanian students were higher than US students.

Our research utilised a new developed survey that collected items from previous research and tried to adapt such items to US and Arabic environment. Still, the instrument needs to be validated more to improve our results. This issue calls for more research on issues related to SNs, or other technologies and how different cultures perceive such technologies. The second limitation of this work is the sample size, where comparable sizes of sample are targeted, which limited our research to a small size. Still, the 
sample size exceeds the recommended size for generalisability (Hair et al., 1998). Finally, future research can contribute to other factors related to using SNs.

\section{References}

Abu-Shanab, E. and Al-Tarawneh, H. (2013) 'How Jordanian youth perceive social networks influence?', Computer Science and Information Technology, Vol. 1, No. 2, pp.159-164.

Abu-Shanab, E. and Al-Tarawneh, H. (2015a) 'The influence of social networks on high school students' performance', International Journal of Web-Based Learning and Teaching Technologies, Vol. 10, No. 2, pp.49-59.

Abu-Shanab, E. and Frehat, M. (2015b) 'The role of social networking in the social reform of young society', International Journal of Technology Diffusion, Vol. 6, No. 1, pp.61-75.

AbuShanab, E., Pearson, J.M. and Setterstrom, A.J. (2010) 'Internet banking and customers' acceptance in Jordan: the unified model's perspective', Communications of the Association for Information Systems, Vol. 26, No. 1, p.23.

Bertot, J.C., Jaeger, P.T. and Grimes, J.M. (2010) 'Using ICTs to create a culture of transparency: E-government and social media as openness and anti-corruption tools for societies', Government Information Quarterly, Vol. 27, No. 3, pp.264-271.

Bolton, R.N., Parasuraman, A., Hoefnagels, A., Migchels, N., Kabadayi, S., Gruber, T., Komarova Loureiro, Y. and Solnet, D. (2013) 'Understanding generation Y and their use of social media: a review and research agenda', Journal of Service Management, Vol. 24, No. 3, pp.245-267.

Brandtzæg, P.B. and Heim, J. (2009) 'Why people use social networking sites', in: International Conference on Online Communities and Social Computing, Springer, Berlin/Heidelberg, pp.143-152.

Brislin, R.W. (1976) 'Comparative research methodology: cross-cultural studies', International Journal of Psychology, Vol. 11, No. 3, pp.215-229.

Chen, H.T. and Kim, Y. (2013) 'Problematic use of social network sites: the interactive relationship between gratifications sought and privacy concerns', Cyberpsychology, Behavior, and Social Networking, Vol. 16, No. 11, pp.806-812.

Dabbagh, N. and Kitsantas, A. (2012) 'Personal learning environments, social media, and selfregulated learning: a natural formula for connecting formal and informal learning', The Internet and Higher Education, Vol. 15, No. 1, pp.3-8.

Dunne, Á., Lawlor, M.A. and Rowley, J. (2010) 'Young people's use of online social networking sites-a uses and gratifications perspective', Journal of Research in Interactive Marketing, Vol. 4, No. 1, pp.46-58.

Fernández, A. (2011) 'Clinical report: the impact of social media on children, adolescents and families', Archivos de Pediatría del Uruguay, Vol. 82, No. 1, pp.31-32.

Frehat, M. and Abu-Shanab, E. (2014) 'The role of social networking in the social reform on young society', Proc. 6th Int. Conf. Manage. Emergent Digital EcoSyst., Al-Qasem, Saudi Arabia, ACM, pp.25-26.

George, D.R. and Dellasega, C. (2011) 'Use of social media in graduate-level medical humanities education: two pilot studies from Penn State College of Medicine', Medical Teacher, Vol. 33, No. 8, pp.e429-e434.

Gikas, J. and Grant, M.M. (2013) 'Mobile computing devices in higher education: student perspectives on learning with cellphones, smartphones \& social media', The Internet and Higher Education, Vol. 19, pp.18-26.

Guàrdia, L., Maina, M. and Sangrà, A. (2013) 'MOOC design principles: a pedagogical approach from the learner's perspective', eLearning Papers, Vol. 33, No. 4, pp.1-6.

Hong, F.Y., Huang, D.H., Lin, H.Y. and Chiu, S.L. (2014) 'Analysis of the psychological traits, Facebook usage, and Facebook addiction model of Taiwanese university students', Telematics and Informatics, Vol. 31, No. 4, pp.597-606. 
Karpinski, A.C., Kirschner, P.A., Ozer, I., Mellott, J.A. and Ochwo, P. (2013) 'An exploration of social networking site use, multitasking, and academic performance among United States and European university students', Computers in Human Behavior, Vol. 29, No. 3, pp.1182-1192.

Kim, Y., Sohn, D. and Choi, S.M. (2011) 'Cultural difference in motivations for using social network sites: a comparative study of American and Korean college students', Computers in Human Behavior, Vol. 27, No. 1, pp.365-372.

Lovejoy, K. and Saxton, G.D. (2012) 'Information, community, and action: how nonprofit organizations use social media', Journal of Computer-Mediated Communication, Vol. 17, No. 3, pp.337-353.

Madge, C., Meek, J., Wellens, J. and Hooley, T. (2009) 'Facebook, social integration and informal learning at university: 'It is more for socialising and talking to friends about work than for actually doing work',' Learning, Media and Technology, Vol. 34, No. 2, pp.141-155.

Moran, M., Seaman, J. and Tinti-Kane, H. (2011) Teaching, Learning, and Sharing: How Today's, Higher Education Faculty Use Social Media, Babson Survey Research Group. Boston, MA.

Park, N., Kee, K.F. and Valenzuela, S. (2009) 'Being immersed in social networking environment: Facebook groups, uses and gratifications, and social outcomes', CyberPsychology and Behavior, Vol. 12, No. 6, pp.729-733.

Parra-López, E., Bulchand-Gidumal, J., Gutiérrez-Taño, D. and Díaz-Armas, R. (2011) 'Intentions to use social media in organizing and taking vacation trips', Computers in Human Behavior, Vol. 27, No. 2, pp.640-654.

Pelet, J.E., Pratt, M.A. and Fauvy, S. (2015) 'MOOCs and the integration of social media and curation tools in e-Learning', Int. Workshop Learn. Technol. Educ. Cloud, Maribor, Slovenia, August 24-28, 2015, Springer International Publishing, pp.43-53.

Peterson, R. and Merunka, D. (2014) 'Convenience samples of college students and research reproducibility', Journal of Business Research, Vol. 67, pp.1035-1041.

Quan-Haase, A. and Young, A.L. (2010) 'Uses and gratifications of social media: a comparison of Facebook and instant messaging', Bulletin of Science, Technology and Society, Vol. 30, No. 5, pp.350-361.

Realo, A., Siibak, A. and Kalmus, V. (2011) 'Motives for Internet use and their relationships with personality traits and socio-demographic factors', Trames, Vol. 15, No. 4, pp.385-403.

Taylor, M. and Kent, M.L. (2010) 'Anticipatory socialization in the use of social media in public relations: a content analysis of PRSA's public relations tactics', Public Relations Review, Vol. 36, No. 3, pp.207-214.

Valenzuela, S., Park, N. and Kee, K.F. (2009) 'Is there social capital in a social network site? Facebook use and college students' life satisfaction, trust, and participation1', Journal of Computer-Mediated Communication, Vol. 14, No. 4, pp.875-901.

Van Dijck, J. (2013) The Culture of Connectivity: A Critical History of Social Media, Oxford University Press. New York, USA.

Whiting, A. and Williams, D. (2013) 'Why people use social media: a uses and gratifications approach', Qualitative Market Research: An International Journal, Vol. 16, No. 4, pp.362-369.

Wu, Y.L., Tao, Y.H., Li, C.P., Wang, S.Y. and Chiu, C.Y. (2014) 'User-switching behavior in social network sites: a model perspective with drill-down analyses', Computers in Human Behavior, Vol. 33, pp.92-103.

Xu, C., Ryan, S., Prybutok, V. and Wen, C. (2012) 'It is not for fun: an examination of social network site usage', Information and Management, Vol. 49, No. 5, pp.210-217. 